\title{
Chronic traumatic and congenital diaphragmatic hernias: Presentation and surgical management
}

\author{
Scott Sattler MD ${ }^{1}$, Timothy G Canty Jr MD ${ }^{1}$, Michael S Mulligan MD ${ }^{1}$, \\ Douglas E Wood MD ${ }^{1}$, J Michael Scully $M D^{2}$, Eric Vallieres $M D^{1}$, \\ Timothy Pohlman MD ${ }^{1}$, Riyad Karmy-Jones MD $^{1}$
}

S Sattler, TG Canty Jr, MS Mulligan, et al. Chronic traumatic and congenital diaphragmatic hernias: Presentation and surgical management. Can Respir J 2002;9(2):135-139.

BACKGROUND: The diagnosis of chronic diaphragmatic hernias, whether due to congenital defects or trauma, may be difficult to make and may rely on clinical suspicion in the setting of persistent nondiagnostic radiographic findings. Repair is indicated to avoid catastrophic cardiopulmonary compromise and/or incarceration of abdominal organs.

STUDY OBJECTIVES: To review the varied presentations and treatment of chronic diaphragmatic hernia.

DESIGN: Retrospective review.

SETTING: University of Washington and Harborview Medical Center, Seattle, Washington.

PATIENTS: Between 1997 and 2001, nine patients presented with chronic diaphragmatic hernia (two congenital cases, seven post-traumatic cases). Four cases involved the right diaphragm. The following clinical features were noted: asymptomatic, chest radiograph showing bowel herniation $(n=1)$; chest wall mass $(n=1)$; asymptomatic with the chest radiograph showing marked elevation of hemidiaphragm $(n=1)$; dyspnea with the chest radiograph showing marked elevation of hemidiaphragm $(n=1)$; diarrhea and heartburn $(n=1)$; generalized gastrointestinal upset $(n=1)$; recurrent pneumonia $(n=2)$; recurring effusions $(n=4)$; and dyspnea on exertion $(n=5)$.
INTERVENTIONS: Diagnosis was confirmed by chest radiograph in two patients, chest computed tomography scan in one patient, barium studies in three patients and thoracoscopy in three patients. All hernias were repaired via thoracotomy, and two hernias were repaired with artificial patch.

CONCLUSIONS: Patients with chronic diaphragmatic hernias present with a variety of symptoms and radiographic findings. When radiology or symptoms suggest bowel involvement, barium studies are appropriate. In other cases, chest computed tomography scans and/or thoracoscopy are useful. Repair is accomplished through the ipsilateral chest, with primary repair of the diaphragm preferred over patch repair.

Key Words: Chronic; Diaphragm; Hernia

Hernies diaphragmatiques chroniques, traumatiques ou congénitales : tableau clinique et traitement chirurgical

CONTEXTE : Le diagnostic des hernies diaphragmatiques chroniques, d'origine traumatique ou congénitale, peut être difficile à poser et parfois on s'en remet à l'intuition clinique dans les cas où les radiogrammes laissent

Résumé a la page suivante

${ }^{1}$ Divisions of Cardiothoracic Surgery, University of Washington and Harborview Medical Center, Seattle, Washington, USA; ${ }^{2}$ General Surgery Kennewick General Hospital, Kennewick, Washington, USA

Correspondence: Dr Riyad Karmy-Jones, Harborview Medical Center, Department of Surgery, Box 359796, 325-9th Avenue, Seattle,

Washington 98104-2420, USA. Telephone 206-731-3000, fax 206-731-3656, e-mail karmy@u.washington.edu 
subsister un doute. La correction est indiquée pour éviter les accidents cardio-pulmonaires dramatiques ou l'étranglement des organes abdominaux. OBJECTIF : Passer en revue les divers tableaux cliniques des hernies diaphragmatiques chroniques et leur traitement.

TYPE D'ÉTUDE : Examen rétrospectif.

LIEU : University of Washington et Harborview Medical Center, Seattle (Washington).

PATIENTS : Neuf patients ont été examinés pour une hernie diaphragmatique chronique (congénitale : 2; traumatique : 7) entre 1997 et 2001. Dans quatre cas, il y avait atteinte du diaphragme droit. Les manifestations cliniques se répartissaient comme suit : absence de symptômes et radiogramme $(\mathrm{RX})$ pulmonaire montrant une hernie intestinale $(\mathrm{n}=1)$; masse sur la paroi de la cage thoracique $(\mathrm{n}=1)$; absence de symptômes et $\mathrm{RX}$ pulmonaire montrant une forte élévation de l'hémidiaphragme $(\mathrm{n}=1)$; dyspnée et RX pulmonaire montrant une forte élévation de l'hémidia- phragme $(\mathrm{n}=1)$; diarrhée et aigreurs $(\mathrm{n}=1)$; troubles gastro-intestinaux généralisés $(n=1)$; pneumonies à répétition $(n=2)$; épanchements récidivants $(n=4)$ et dyspnée d'effort $(n=5)$.

INTERVENTIONS : Le diagnostic a été confirmé par radiographie pulmonaire chez deux patients, tomodensitométrie thoracique chez un patient, transit baryté chez trois patients et thorocoscopie chez trois patients. Toutes les hernies ont été corrigées par thoracotomie et deux ont nécessité la pose d'une pièce artificielle.

CONCLUSIONS : Les patients porteurs d'une hernie diaphragmatique chronique présentent des symptômes et des signes radiographiques très variés. Dans les cas où les radiogrammes ou les symptômes laissent supposer une atteinte intestinale, le transit baryté est approprié. Dans d'autres cas, la tomodensitométrie thoracique ou la thorocoscopie conviennent mieux. On procède à la correction par voie ipsilatérale, et la réparation du diaphragme est préférable à la pose de pièces.
$\mathrm{T}$ he presentation of chronic diaphragmatic hernias may vary from an asymptomatic chest radiograph abnormality to septic shock due to intestinal infarction (1-4). They may be a consequence of congenital diaphragmatic herniation presenting in a delayed fashion or missed traumatic injuries. Because of the passage of time, patients often present not to surgeons, but to family practitioners, internists or respirologists with recurring pulmonary and/or gastrointestinal complaints. Making the diagnosis is important because of the potential for complications, and repair should be considered, even in asymptomatic patients. Confirming the diagnosis by noninvasive means may be difficult, however, because radiology has relatively low sensitivity and specificity. Nine cases that illustrate the varied presentations are presented, and diagnosis and treatment are discussed.

\section{CASE PRESENTATIONS}

Nine cases of chronic diaphragmatic hernia were compiled between 1997 and 2001 at the University of Washington Medical Center and Harborview Medical Center, Seattle, Washington (Table 1).

Two patients with congenital defects (patients 2 and 5) presented with respiratory complaints; in both patients, incarcerated small and large bowels were present. Both were repaired via thoracotomy, one with a patch, and patient 5 also required a laparotomy to correct malrotation. After four years of follow-up, both patients remain symptom-free.

Seven patients presented after blunt trauma, with presentation ranging from five months to 40 years after the event. All but one patient had respiratory complaints (Table 1). All patients were repaired via thoracotomy. In

\section{TABLE 1}

Case descriptions of nine patients with diaphragmatic hernias at the University of Washington Medical Center and Harborview Medical Center, Seattle, Washington, between 1997 and 2001

\begin{tabular}{|c|c|c|c|c|c|c|}
\hline $\begin{array}{l}\text { Patient (age } \\
\text { in years, } \\
\text { sex) }\end{array}$ & $\begin{array}{c}\text { Side of } \\
\text { hemidiaphrag }\end{array}$ & Etiology & $\begin{array}{l}\text { Clinical } \\
\text { presentation }\end{array}$ & Organs herniated & $\begin{array}{c}\text { Study } \\
\text { confirming } \\
\text { diagnosis }\end{array}$ & $\begin{array}{l}\text { Surgical } \\
\text { repair }\end{array}$ \\
\hline $1(22$, male $)$ & Right & Trauma six years earlier & Heartburn, effusion, anemia & Stomach, colon & UGI & Primary \\
\hline $2(53$, male $)$ & Left & Trauma 15 years earlier & Recurrent hemothorax & Spleen & VATS & Primary \\
\hline 3 (8, female) & Right & Congenital & Recurrent pneumonia, asthma & $\begin{array}{l}\text { Small bowel, liver, } \\
\text { colon, stomach }\end{array}$ & UGI & Primary \\
\hline $4(76$, male $)$ & Right & Trauma 40 years earlier & Asymptomatic CXR after CABG & $\begin{array}{l}\text { Small bowel, liver, } \\
\text { colon, kidney }\end{array}$ & CXR & Patch \\
\hline 5 (40, female) & Left & Congenital & Short of breath on exertion & Small bowel, colon, kidney & y CXR & Patch \\
\hline $6(42$, male $)$ & Left & Trauma 20 years earlier & Short of breath on exertion & Stomach, colon & VATS & Primary \\
\hline $7(60$, male $)$ & Left & Trauma five months earlier & $\begin{array}{l}\text { Short of breath on exertion, } \\
\text { cor pulmonale, recurrent effusion }\end{array}$ & Omentum & VATS & Primary \\
\hline 8 (41, female) & Right & Trauma nine years earlier & $\begin{array}{l}\text { Short of breath on exertion, } \\
\text { cor pulmonale, gastrointestinal upse }\end{array}$ & Liver, colon & CT & Primary \\
\hline 9 (51, male) & Right & Trauma two years earlier & Chest wall mass & Liver, colon, small bowel & CT & $\begin{array}{l}\text { Primary with } \\
\text { hest wall patch }\end{array}$ \\
\hline
\end{tabular}


one patient (patient 9), an attempt had been made to reduce the defect through laparotomy, but the attempt failed due to extensive adhesions. In two patients, both with morbid obesity, the diagnosis could not be made by chest radiography, but was confirmed by computed tomography $(\mathrm{CT})$ scan in one case and by thoracoscopy in the second case. These patients were the only two to experience complications. One patient (patient 8) developed an acute pulmonary saddle embolism on the second postoperative day, requiring urgent surgical clot removal. Patient 7 experienced progressive right heart failure complicated by pre-existing sleep apnea, and after refusing any further intervention, died two months after repair. All of the other patients are doing well, with resolution of respiratory complaints noted at follow-up visits ranging from six months to four years after repair.

\section{DISCUSSION}

\section{Pathophysiology of diaphragmatic hernias}

As opposed to hiatus hernias, congenital and traumatic diaphragmatic hernias result from defects in the musculotendinous membrane rather than from dilation of normally occurring diaphragm openings. The diaphragm is subjected to radial forces such that a small defect tends, over time, to enlarge, leading to two broad classes of complications. The first is related to the inability to generate normal, effective diaphragmatic contraction, leading to weak inspiratory and expiratory strength, and thus, to decreased exercise capacity in conjunction with increasing dyspnea. This is similar to the problems encountered with diaphragmatic eventration and phrenic nerve paralysis. The second complication relates to migration of abdominal contents into the chest (liver and colon on the right; stomach, spleen, small bowel and colon on the left). A pressure gradient of 7 to $20 \mathrm{~cm} \mathrm{H}_{2} \mathrm{O}$ normally exists between the abdominal (more positive) and thoracic compartments. This gradient can increase to as much as $100 \mathrm{~cm} \mathrm{H}_{2} \mathrm{O}$ in deep inspiration or with other conditions, including pregnancy, that increase intra-abdominal pressure (1-7). As abdominal contents fill the thoracic cavity, cardiac and respiratory functions become compromised. In addition, the colon and/or small bowel can become incarcerated, leading to a pattern of abdominal complaints, bowel obstruction, and eventually, perforation and septic shock.

\section{Chronic traumatic diaphragmatic hernias: \\ Clinical presentation}

Delayed post-traumatic chronic diaphragmatic hernias are usually defined as those in which the diagnosis is made more than one month after the injury (8), and the onset of symptoms can be delayed by as much as 40 years. The true incidence of this entity is hard to define with certainty. Shah and associates (8) reviewed 980 patients with traumatic diaphragmatic injuries reported in the literature, and noted that the diagnosis was made preoperatively in $43.5 \%$ of patients, and at surgery or autopsy in $41.9 \%$; in the remaining $14.6 \%$, the diagnosis was delayed. Maekawa and associates (9) noted that over an 18-year period in Japan, 297 cases of blunt traumatic diaphragmatic hernias were reported, of which 47 cases ( 32 in left hemidiaphragm, 15 in right hemidiaphragm) were delayed (9). Chronic post-traumatic diaphragmatic hernias are a consequence of blunt injury in three-quarters of cases (10). A number of similar cases related to penetrating injuries have been described as well.

When due to trauma, the left hemidiaphragm is more often affected (1). This has been variously attributed to the 'protective' effect of the liver in blunt trauma and to congenitally weak attachments of the left diaphragm. Mansour noted that of 15 patients with chronic post-traumatic diaphragmatic hernias, 13 had hernias that involved the left side and four had hernias that followed penetrating trauma (11). With penetrating diaphragmatic injuries, left-sided lesions may be associated with a preponderance of righthanded assailants (11-14).

The broad range of patient complaints in the setting of chronic traumatic diaphragmatic hernias reflects the variety of herniated structures found in these patients. Traumatic chronic diaphragmatic hernias may be asymptomatic in up to $20 \%$ of cases, may occasionally masquerade as acute pneumonia and may present with gastrointestinal symptoms of varying severity in up to $70 \%$ of cases, including incarcerated abdominal viscera in $30 \%$ to $50 \%$ of cases $(1,2,11,15)$. In the series reported by Hegarty et al (2), $72 \%$ of patients presented with herniated colon, $40 \%$ presented with herniated stomach, $16 \%$ presented with small bowel and $8 \%$ presented with spleen herniations. Most patients present with hernias of mixed content, as demonstrated in the present series (Table 1).

\section{Chronic congenital diaphragmatic hernias: Clinical presentation}

There is no widely accepted definition for a chronic congenital diaphragmatic hernias. Congenital diaphragmatic hernias recognized in a delayed fashion can present after the first few days of life to several months or years after birth. Congenital diaphragmatic hernias are diagnosed beyond the first hours of life in only $10 \%$ to $20 \%$ of recognized cases (4). The present series includes two patients with chronic congenital diaphragmatic hernias - an eightyear-old child and a forty-year-old woman (Table 1).

Congenital diaphragmatic hernias include the anterior foramen of Morgagni and the more common posterolateral foramen of Bochdalek defects. The left side is much more commonly affected than the right. In three series reported in the 1990s comprising 23 patients, 17 defects were left posterolateral, four were right-sided and two were anterolateral in the area of the foramen of Morgagni (16-18). Malone and associates (3) described a series of 22 patients with chronic congenital diaphragmatic hernias; $46 \%$ had a Bochdalek hernia, $23 \%$ had a central hernia related to agenesis of the diaphragm, $13 \%$ had a Morgagni hernia and $18 \%$ had an eventration of the diaphragm.

Virtually all patients with chronic congenital diaphragmatic hernias present with pulmonary complaints, in addition to suffering from a high incidence of gastrointestinal 


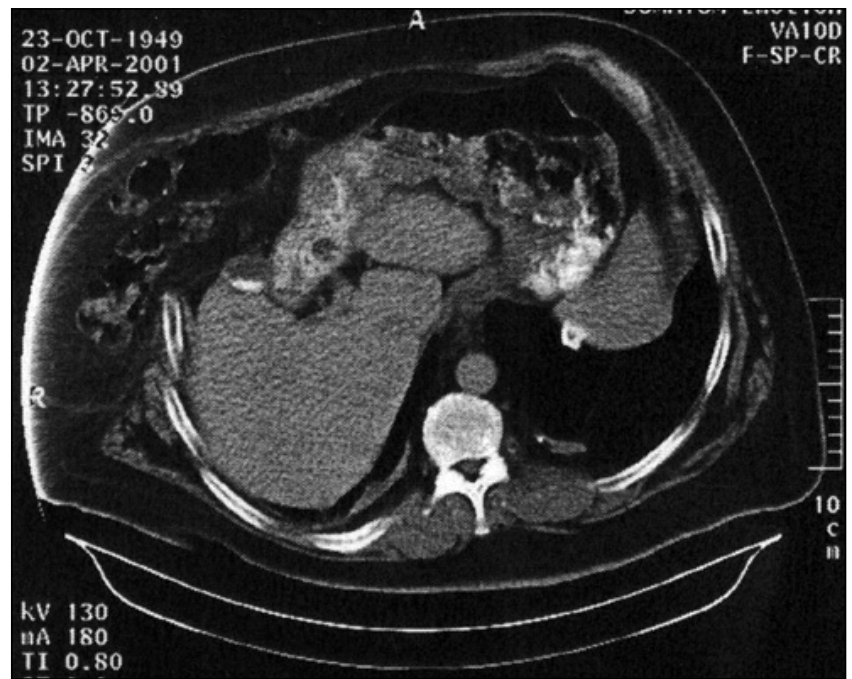

Figure 1) Chest computed tomography scan demonstrating bowel herniating through the diaphragm and a chest wall defect

symptoms varying from failure to thrive to frank bowel obstruction. Intestinal obstruction is less likely with chronic congenital diaphragmatic hernias compared with chronic traumatic diaphragmatic hernias because of an associated hernia sac in congenital lesions. Children with gastrointestinal complaints tend to be older than the age of one year. Younger patients present with acute respiratory problems. Virtually all patients with posterolateral diaphragmatic defects have respiratory complaints, ranging from 'pneumonia' to 'tension pneumothorax' (16-19). In sharp distiction, an anterior Morgagini hernia is more likely to present as an asymptomatic mass or a cardiophrenic shadow (3).

\section{Recognizing chronic congenital and traumatic diaphragmatic hernias}

A number of factors contribute to delayed diagnosis of chronic diaphragmatic hernias, including lack of documentation of previously normal radiographic studies; prolonged period of time between the inciting event (in the case of trauma) and presentation; failure to recognize that the entity exists (as in congenital diaphragmatic hernias); and the misdiagnosis of radiographic findings. The key to diagnosing post-traumatic diaphragmatic hernias is obtaining a history of trauma. It is important to note that acute diaphragmatic injuries can be missed at laparotomy $(8,11)$. The diagnosis of chronic congenital diaphragmatic hernia rests on the exclusion of other causes for the diaphragmatic hernia. If no history of abdominal trauma can be elicited, the case for a congenital etiology is supported. Surgical exploration and repair confirm the diagnosis if the position of the lesion appears to be consistent with diaphragmatic eventration, or a Morgagni or Bochdalek hernia.

The diagnosis of chronic diaphragmatic hernia relies heavily on radiography. Chest radiographs are diagnostic in only $25 \%$ to $50 \%$ of cases $(11,19)$. Patients who present with primarily intestinal complaints and a radiological pat- tern suggesting 'gas' above the diaphragm (including a nasogastric tube in the chest) should be evaluated with a barium enema and/or upper gastrointestinal series to evaluate the stomach and small bowel $(19,20)$. Upper gastrointestinal series should be included in all cases of congenital chronic diaphragmatic hernia to exclude associated malrotation (3). Patients who present with less specific complaints and who only have suggestive radiographic changes (pleural mass, recurrent effusions, elevated diaphragm, cystic lower lobe mass) or who present with 'complex pleural space' problems with no gastrointestinal signs or symptoms should be studied by CT scans of the chest with oral contrast (Figure 1). Studies of acute traumatic diaphragmatic injury suggest that CT scans have a sensitivity of approximately $80 \%$ for detecting left-sided lesions, but only $50 \%$ for detecting right-sided lesions. This is because the major diagnostic sign is constriction of abdominal viscera (the 'collar sign') or presence of hollow viscera in the chest. Diaphragmatic defects can be detected but are difficult to clearly delineate by CT scan (21).

In the setting of chronic diaphragmatic hernias, there is an increased incidence of abdominal visceral herniation recognizable on a CT scan. If the CT scan is suggestive of such a hernia, magnetic resonance imaging has proven to be effective in diagnosing small defects. Fluoroscopy is useful in determining abnormal diaphragmatic excursion, which may suggest an injury or defect, but it has a similar sensitivity and specificity to chest radiography $(8,11)$. For patients who may have a post-traumatic chronic diaphragmatic hernia, thoracoscopy (and occasionally laparoscopy) has proven to be an effective, minimally invasive method of confirming the diagnosis. Thoracoscopy is used in patients who have soft findings on a chest radiograph, often after an equivocal CT scan. Thoracoscopy can be used to repair defects in some cases in which adhesions are not severe.

\section{Operative approach to chronic diaphragmatic hernias}

When a chronic traumatic diaphragmatic hernia is diagnosed, repair is usually performed via the ipsilateral chest, because there are usually dense adhesions between the viscera and lung that preclude safe transabdominal reduction. Reducing a herniated viscus through an abdominal approach risks excessive pulling and tearing of the viscus, which could potentially spill intestinal contents into the pleural space. Rarely, a thoracoabdominal incision is needed, although it is best to avoid this because of the risk of phrenic nerve injury and of creating another diaphragmatic defect (14).

The operative approach in the congenital setting depends on whether malrotation is present (present in up to one-third of patients), in which case, an abdominal approach is also needed to divide Ladd's bands (3). Primary repair can be performed in the majority of cases (with or without pledgets), but in some cases, artificial material is required $(8,9,16-18)$. There is some experimental evidence suggesting that repairing the defect with prosthetic material may result in better respiratory muscle function, but this has not been studied clinically, and in general, we prefer to 
avoid the risk of foreign material if a tension-free repair can be achieved (22).

\section{CONCLUSIONS}

Chronic diaphragmatic hernias, whether of traumatic or congenital origin, have a variety of presentations, ranging from asymptomatic radiographic changes to shock. The broad range of patient complaints in the setting of chronic diaphragmatic hernias reflects the variety of herniated structures found in these patients. Patients with congenital defects tend to present with respiratory symptoms and chest radiographic findings that are confused with pneumonia or other processes. Traumatic injuries are often asymptomatic, and chest radiographs reveal only nonspecific findings. Patients with either type of chronic diaphragmatic hernias are at risk of developing either severe cardiopulmonary

\section{REFERENCES}

1. Reber PU, Schmeid B, Seiler CA, et al. Missed diaphragmatic injuries and their long-term sequelae. J Trauma 1998;44:183-8.

2. Hegarty MM, Bryer JV, Angorn IB, et al. Delayed presentation of traumatic diaphragmatic hernia. Ann Surg 1978;188:229-33.

3. Malone PS, Brain AJ, Kiely EM, et al. Congenital diaphragmatic defects that present late. Arch Dis Child 1989;64:1542-4.

4. Manning PB, Murphy JP, Raynor SC, et al. Congenital diaphragmatic hernia presenting due to gastrointestinal complications. J Pediatr Surg 1992;27:1225-8.

5. Waldhausen, JA, Kilman JW, Helman CH, et al. The diagnosis and management of traumatic injuries of the diaphragm including the use of Marlex prostheses. J Trauma 1966;6:332-43.

6. Waldschmidt, ML, Laws HL. Injuries of the diaphragm. J Trauma 1980;20:587-91.

7. Kurzel RB, Naunheim KS, Schwartz RA. Repair of symptomatic diaphragmatic hernia during pregnancy. Obstet Gynecol 1988;71:869-71

8 Shah R, Sabanathan S, Mearns AJ, Choudhry AK. Traumatic rupture of diaphragm. Ann Thorac Surg 1995;60:1444-9.

9. Maekawa T, Yabuki K, Satou K, et al. A patient with a traumatic right diaphragmatic hernia occurring 4 years after sustaining injurystatistical observations of a delayed diaphragmatic hernia caused by uncomplicated injury in Japan. Nippon Geka Hokan 1997;66:116-25.

10. Feliciano DV, Mattox KL, Bitondo CG, et al. Delayed diagnosis of injuries to the diaphragm after penetrating wounds. J Trauma 1988;28:1135-44.

11. Mansour KA. Trauma to the diaphragm. Chest Surg Clin N Am 1997;7:373-83. compromise or complications related to incarceration of abdominal organs. CT scans of the chest are used to evaluate patients who present with respiratory or gastrointestinal symptoms and a chest radiograph suggestive of an intestinal gas pattern in the thorax. For patients with persistent respiratory or abdominal complaints and unclear CT scan findings, diagnostic thoracoscopy should be considered. Repair of a chronic diaphragmatic hernia is safest through the ipsilateral thorax, and primary repair of the diaphragmatic defect is preferred, although patch repairs can be used for larger defects.

Of note, many patients do not present to surgeons, but rather, to internists or pediatricians. In the present series, all but two patients were managed initially by nonsurgeons, underlying the need for all physicians to be aware of the possibility of this condition.

12. Sharma OP. Traumatic diaphragmatic rupture: Not an uncommon entity - Personal experience with collective review of the 1980s. J Trauma 1989;29:678-82.

13. Hood RM. Traumatic diaphragmatic hernia. Ann Thorac Surg 1971:12:311-24

14. Thal ER, Provost DA. Traumatic Rupture of the Diaphragm. Mastery of Surgery, Volume 1, 3rd edn. Boston: Little, Brown and Company Inc, 1997:686-93.

16. Numanoglu A, Steiner Z, Millar A, et al. Delayed presentation of congenital diaphragmatic hernia. S Afr J Surg 1997;35:74-6.

17. Fotter R, Schimpl G, Sorantin E, et al. Delayed presentation of congenital diaphragmatic hernia. Pediatr Radiol 1992;22:187-91.

18. Delport SD. Aftermath of failed diagnosis of late-presenting congenital diaphragmatic hernias. S Afr J Surg 1996;34:69-72.

15. Carter BN, Giuseffi J, Felson B. Traumatic diaphragmatic hernia. AJR Am J Roentgenol 1951;65:56-72.

20. McHugh K, Ogilvie BC, Brunton FJ. Delayed presentation of traumatic diaphragmatic hernia. Clin Radiol 1991;43:246-50.

19. Gayer G, Bilik R, Vardi A. CT diagnosis of delayed presentation of congenital diaphragmatic hernia simulating massive pleuropneumonia. Eur Radiol 1999;9:1672-4.

21. Lin YK, Huang BS, Shih CS, Hsu WH, Huaug MH, Lee CH. Traumatic diaphragmatic hernia with delayed presentation. Zhonhua Yi Xue Za Zhi (Taipei) 1999;62:223-9.

22. Menezes SLS, Chagas PSC, Macedo-Neto AV, et al. Suture or prosthetic reconstruction of experimental diaphragm defects, respiratory repercussions. Chest 2000;117:1443-6. 


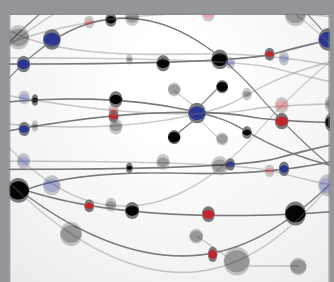

The Scientific World Journal
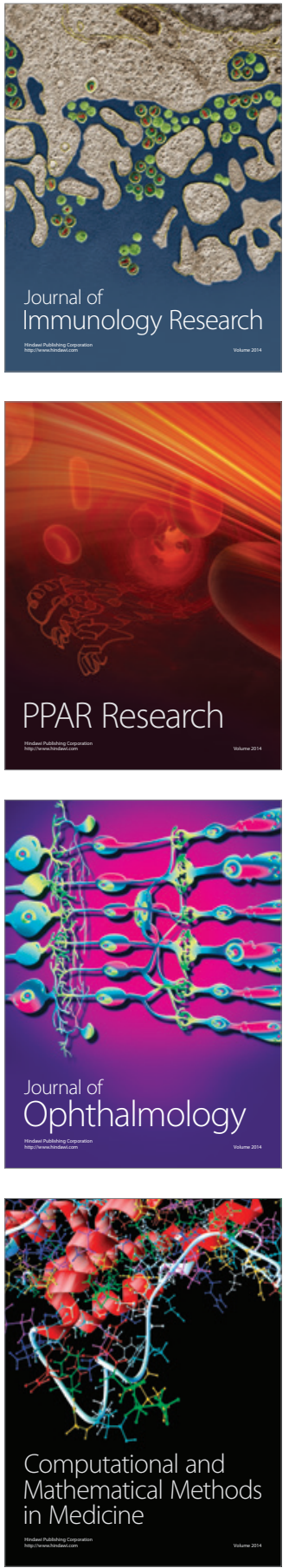

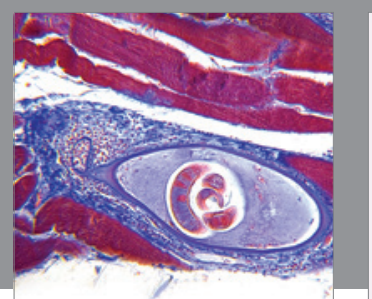

Gastroenterology Research and Practice

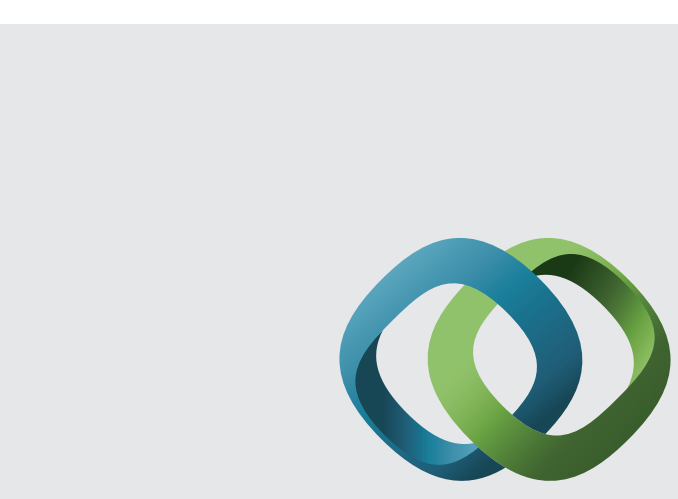

\section{Hindawi}

Submit your manuscripts at

http://www.hindawi.com
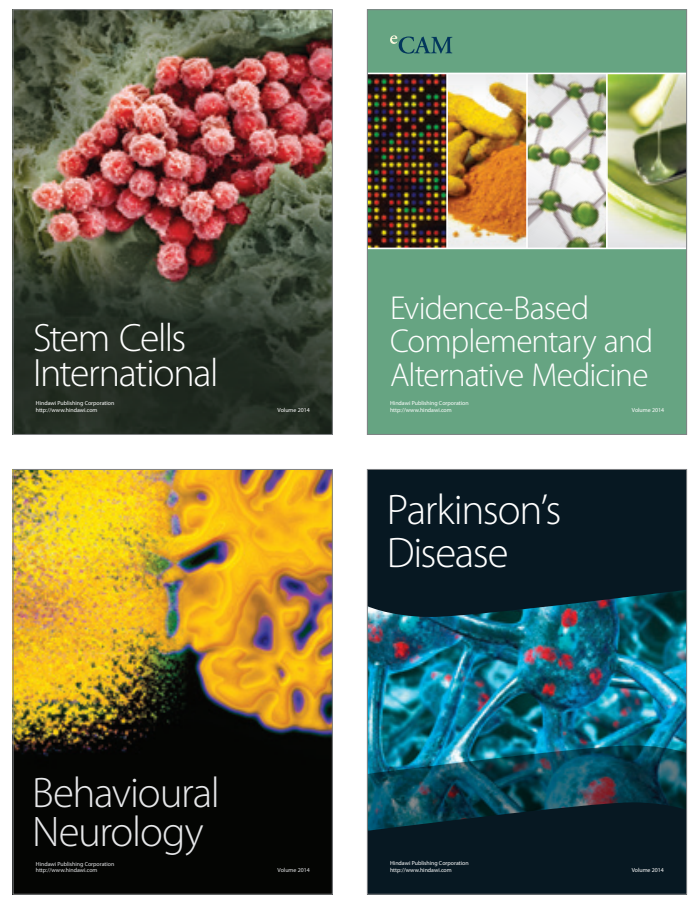
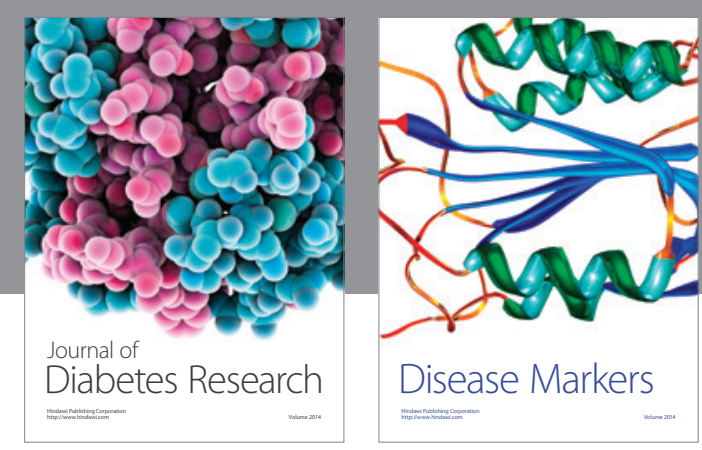

Disease Markers
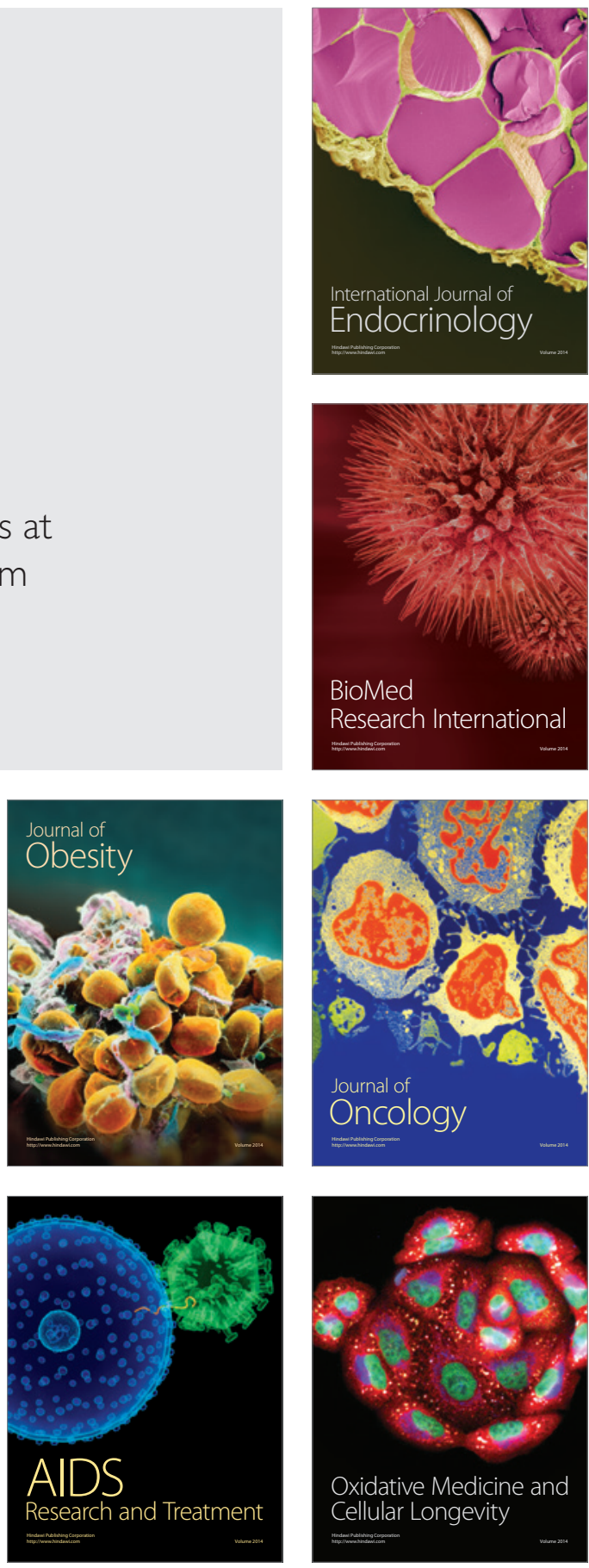